\title{
Changes in young women's contraceptive use in the Netherlands: findings from three sex under the age of 25 surveys
}

\author{
Elske Marra', Suzanne Meijer ${ }^{2}$ and Hanneke de Graaf ${ }^{1 *}$ (D)
}

\author{
* Correspondence: h.degraaf@ \\ rutgers.nl \\ ${ }^{1}$ Rutgers, Programme Knowledge \\ Development, Utrecht, The \\ Netherlands \\ Full list of author information is \\ available at the end of the article
}

\begin{abstract}
Prevention of unintended pregnancy among adolescents and young adults under 25 years is pivotal from an individual as well as societal perspective. In the USA, the use of long-acting reversible contraceptive (LARC) has been shown to increase, with no or little change in the use of short-acting reversible contraceptive (SARC). We assessed trends in no contraceptive, SARC, and LARC use by young women, aged between 12 and 25 years, and differences in trends within demographic groups (age, religion, ethnic background, and educational level) among these young women in the Netherlands. Data of sexually active young women aged 12-25 years from three cross-sectional representative surveys, 2005, 2012, and 2017, were used for this study. In total, 11,229 Dutch young women were included with a median age of 20 years (interquartile range 18-23 years). Overall, the proportion of young women using SARC decreased significantly between 2005 and 2017 from 88 to 76\%. LARC use increased significantly between 2005 and 2017 from 3 to 16\%. These trends varied by religious groups and educational level, emphasizing potential for tailored preventative measures for these groups. A shift towards LARC use might eventually lead to a further decrease in unwanted pregnancy and potentially abortion because of the lower risk of user errors.
\end{abstract}

Keywords: Contraception, Young women, Adolescents, LARC, Trends, Populationbased survey

\section{Introduction}

In Western countries, contraceptives are widely used. According to estimates of the United Nations, approximately $49 \%$ of women living in Europe aged 15-49 years used modern contraceptives in 2019 (United Nations, 2019). Modern methods of contraception include female and male sterilization, oral hormonal pill, vaginal ring, the intrauterine device, male and female condom, injectable, implant, vaginal barrier method, standard day method, lactational amenorrhea method, and emergency contraception. Traditional methods of contraception include (periodic) abstinence, the withdrawal method, the rhythm method, douching, and folk methods (Cahill et al., 2018). As shown by the various modern contraceptive methods, choice of contraceptive method

(c) The Author(s). 2020 Open Access This article is licensed under a Creative Commons Attribution 4.0 International License, which permits use, sharing, adaptation, distribution and reproduction in any medium or format, as long as you give appropriate credit to the original author(s) and the source, provide a link to the Creative Commons licence, and indicate if changes were made. The images or other third party material in this article are included in the article's Creative Commons licence, unless indicated otherwise in a credit line to the material. If material is not included in the article's Creative Commons licence and your intended use is not permitted by statutory regulation or exceeds the permitted use, you will need to obtain permission directly from the copyright holder. To view a copy of this licence, visit http://creativecommons.org/licenses/by/4.0/. 
is diverse. Which contraceptive method is chosen is a personal choice, but often influenced by co-factors, like finances, accessibility, and availability (Deitch \& Stark, 2019; Ponce de Leon et al., 2019; Ugaz, Chatterji, Gribble, \& Mitchell, 2015). Short-acting reversible contraceptives (SARCs) like oral contraception pills and the vaginal ring, tend to be used more than long-acting reversible contraceptives (LARCs) like intrauterine devices (Daniels, Daugherty, Jones, \& Mosher, 2015; Darroch \& Singh, 2013; Hopkins et al., 2018; Ponce de Leon et al., 2019; Ugaz et al., 2015). However, LARCs have some advantages compared to SARC, specifically in effectiveness, safety, cost-effectiveness, and once inserted they are independent of user compliance or correct usage (Shoupe, 2016; Stoddard, McNicholas, \& Peipert, 2011; Walsh et al., 2004). Therefore, the 12month typical-use contraceptive failure rates are 4 to 9 times higher for SARC than for LARC (Polis et al., 2016).

Contraceptive use in the Netherlands is high. In 2017, $92 \%$ of young men and $94 \%$ of young women aged 12 to 25 years reported to have used any contraceptive during their first intercourse (De Graaf, Verbeek, Van den Borne, \& Meijer, 2018). Trends in the Netherlands show a stable prevalence of modern contraceptive use between 65 and $70 \%$ among women aged 15 to 49 years since approximately 1980 (United Nations, 2019). In a European survey in 20 European countries, the Netherlands appeared to have the third highest level of contraceptive use at last intercourse among 15-year olds (Inchley et al., 2016). The high contraceptive use in the Netherlands contributes to teenage pregnancy and abortion rates that are among the lowest in the world (Sedgh, Finer, Bankole, Eilers, \& Singh, 2015). However, the vast majority of Dutch women uses oral contraceptives, a method with relatively high contraceptive failure rates. Therefore, a shift towards LARC use could also lower unintended pregnancy rates within this country. Prevention of unintended pregnancy is pivotal from an individual as well as societal perspective (Davtyan, 2000). For example, women with unplanned pregnancy engage fewer in healthy practices and experience more depressive symptoms during pregnancy (Karaçam \& Ançel, 2009; Yanikkerem, Ay, \& Piro, 2013).

The potential benefits of shifting towards LARC use highlight the importance of assessing recent trends in these types of contraceptives. In the USA recently, no or small changes were seen in the proportion of women using SARC, but an increase in the use of LARC as a contraceptive has been shown (Daniels et al., 2015; Ihongbe \& Masho, 2017; Kavanaugh \& Jerman, 2018; Lindberg, Santelli, \& Desai, 2018). At the same time teenage pregnancy rates decreased, which could be explained by increases in LARC use (Ngui, Greer, Bridgewater, Salm Ward, \& Cisler, 2017). This increase in LARC use has been shown in other countries as well (Adedini, Omisakin, \& Somefun, 2019; Connolly, Pietri, Yu, \& Humphreys, 2014; Moreau, Bohet, Hassoun, Teboul, \& Bajos, 2013; Pazol, Daniels, Romero, Warner, \& Barfield, 2016), sometimes combined with data showing a decrease in unplanned pregnancies and abortion rates (Connolly et al., 2014). Recent trends were also shown for SARC (Kinoshita, Tanaka, Inagaki, Takeuchi, \& Kawakami, 2018; Rodriguez, Abutouk, Roque, \& Sridhar, 2015) or oral contraceptives only (Carrasco-Garrido et al., 2016).

As shown in previous studies, trends in SARC and LARC use are not equally large in all demographic groups (i.e., based on age, religion, educational level, ethnicity, or partner status). In general, LARC use was found to be more prevalent among women over 19 years (Daniels et al., 2015; Moreau et al., 2013; Ponce de Leon et al., 2019), more 
educated women (Ihongbe \& Masho, 2017; Kramer, Higgins, Godecker, \& Ehrenthal, 2018; Ponce de Leon et al., 2019) and women in a steady relationship (Moreau et al., 2013; Walsh-Buhi \& Helmy, 2018). General contraceptive use was found to be lower among religious young women (Moreau et al., 2013), but LARC use per se does not seem to be related to religion (Kramer et al., 2018). In the USA, black women were found to use LARC less often (Kramer et al., 2018) or similar (Ihongbe \& Masho, 2017) compared to white and Hispanic women. It is not clear, however, how these ethnic groups compare to those in the Netherlands, although the higher prevalence of repeat abortions among women from Moroccan, Turkish, Surinamese or Antillean descent suggests that their contraceptive choices might be less effective (Picavet, Goenee \& Wijsen, 2013). However, all these differences in usage do not inform us about differences in trends in contraceptive methods. For example, Kavanaugh and Jerman (2018) found that IUD use was related to several demographic variables, but that the increase in IUD was similar in all groups regardless of these characteristics. Demographic differences in trends over time are rarely studied and if they are, trends were generally similar in different demographic groups (Adedini et al., 2019; Kavanaugh \& Jerman, 2018).

Research into recent trends in modern contraceptive use in the Netherlands is lacking. We assessed trends in types of modern contraceptives used among young women, aged 12 to 25 years, in the Netherlands who at least once experienced sexual intercourse (penile-vaginal penetration). In order to tailor specific and targeted preventive efforts to demographic groups that lag behind in the shift towards LARC methods, insight in differences in trends in contraceptive use is important. Therefore, the second purpose of this paper is to assess differences in trends of no contraceptive use, SARC, and LARC use by demographic factors among young women in the Netherlands.

\section{Methods}

\section{Sample}

In the Netherlands, a national population survey into the sexual health of young people aged 12 to 25 years has been conducted in 2005, 2012, and 2017, titled "Sex under the age of 25." Data for these studies were collected from young people aged 12 to 25 years using two methods: (1) through randomly selected schools (aged 12-17 years) and (2) from a random sample drawn from the municipal population registers (aged 17-25 years). Recruitment of schools was based on the distribution of students over school year and school type that matched with the distribution among all students in Dutch secondary education. Within every school, three to four classes were randomly selected, depending on the size of the school. If a selected school was unable or unwilling to participate, a comparable school in the same region was selected. Participants recruited via schools completed this questionnaire during a regular class period, whereas participants recruited via the municipal population registers received a letter of invitation (and up to two reminders among non-responders) and completed the questionnaire at home. The method of data collection was described in more detail in previous publications (De Graaf et al., 2018; De Graaf, Vanwesenbeeck, \& Meijer, 2014; De Graaf, Vanwesenbeeck, Meijer, Woertman, \& Meeus, 2009).

In total, 29 schools participated in 2005, 43 schools in 2012, and 106 schools in 2017. 
Concerning the recruitment from municipal population registers, in 2005 12,460, in 2012 33,000, and in 2017 17,368 invitation letters were send. Non-responders were reminded twice. In every year of data collection, but especially in 2017, municipal health services recruited extra participants in their own region. Weighting techniques were applied to all three datasets, to correct for selective non-response as well as for oversampling in some regions. Therefore, each sample was representative for the Dutch population aged 12-25 in that particular year with regard to age, educational level, and ethnic background. The total number of young people who completed the questionnaire was 4820 in 2005, 7841 in 2012, and 20,840 in 2017.

\section{Measures}

All participants completed the same online questionnaire including questions on a broad range of sexual health themes. In the current study, the following measures were included in the analyses:

age, which was measured in or recoded to whole years.

Educational level. Participants were classified as "less educated" if they were enrolled in prevocational or secondary vocational education or if they were no longer enrolled in school and had completed pre-university education at most. Participants were classified as "more educated" if they were enrolled in general secondary, pre-university, higher professional or university education or if they were higher professional or university graduates.

Religion was a combined measure of two questions: (1) whether religion was important to the participant with (2) self-reported religion. This combined measure was recoded into five categories $(1=$ not religious; $2=$ Christian, some importance; $3=$ Christian, very important; $4=$ Muslim; $5=$ Other). Because of the very few Muslim participants who attached merely some importance to religion, we were not able to distinguish levels of importance within this group.

Ethnicity was based on country of birth of the participant and of his or her parents. If a participant was born outside of the Netherlands, the country of birth was leading in determining ethnicity; otherwise, the country of birth of the mother was leading, unless the mother was born in the Netherlands. In that case, country of birth of the father was leading.

Partnership status shows whether participants were in a relationship when they completed the questionnaire.

Contraceptive use, the outcome measure, was assessed in the survey with two questions "Do you currently use contraceptives?", and if yes, "What contraceptive method are you currently using?". Young women could choose between no contraceptive use, oral contraceptives, condoms, oral contraceptives and condoms, injectable contraceptives, contraceptive patch, contraceptive ring, contraceptive implant, intrauterine device, and other contraceptive. In analyses, this outcome measure was categorized into the following: no contraceptive use, short-acting contraceptive use (including condoms, oral-, injectable-, vaginal ring-, and patch contraceptives), and long-acting contraceptive use (including contraceptive implants and intrauterine devices).

Due to routing in the questionnaire, this question was only asked to young women with experience of sexual intercourse (penile-vaginal penetration). Young women who 
did not use any contraceptive and indicated that the reason for this was a lack of current sexual activity (with males) were excluded from analyses, since there is no risk for unintended pregnancy.

Year of participation, i.e., 2005, 2012, or 2017.

\section{Statistical analyses}

The different years of data collection were compared on demographics using chisquared tests and type of contraception was compared by Fisher-exact tests due to limited use of some contraception methods.

Trends over time in types of contraceptive methods used (no contraceptive use, SARC use, and LARC use) were assessed for the total sample and for the separate demographic groups, using non-parametric test for trend based on the Wilcoxon method (Cuzick, 1985).

Since demographic factors included in this analysis might not be independent, univariable and multivariable multinomial logistic regression was performed to assess whether year of inclusion is associated with type of contraceptive used while controlling for demographic factors.

To assess if use of contraceptive method differed between groups within a demographic variable over time, multivariable multinomial logistic regression, including a demographic variable and inclusion year, was performed in which interaction was tested between the demographic variable and inclusion year. Due to power limitations, specifically in some religious and ethnic groups, a multivariable multinomial logistic regression including all demographic variables as well as interaction of one of the demographic variables and inclusion year could not be performed.

A significance level of 0.01 was used to compensate for the large sample size and multiple testing. Based on the increased power required for interaction testing and limited number of interaction tests performed, we used a significance level of 0.05 for interaction testing. Weighting techniques were applied to all analyses in order to ensure representativeness of the Dutch population. All analyses were performed using the SPSS (IBM Corp. Released 2018. IBM SPSS Statistics for Windows, version 25.0. Armonk, NY: IBM Corp.) and R Statistical Software (version 3.6.1).

\section{Results}

\section{Study participation}

Over the years, in total, 11,668 Dutch young women aged 12 to 25 years who had at least once experienced sexual intercourse (penile-vaginal penetration) participated in the "Sex under the age of 25 " studies. Within this group, 441 young women indicated not using contraceptives because they (currently) did not have sexual intercourse with a male partner, resulting in 11,227 young women included in this study. Of these young women, 1223 participated in 2005, 2726 in 2012, and 7278 in 2017.

\section{Characteristics of the study population}

The young women in our final sample had a median age of 20 years (interquartile range (IQR) 18-23 years). In 2017, less participants were aged $\leq 18$ years and more participants were aged $\geq 22$ years (Table 1 ). These age differences can be ascribed to an 
Table 1 Characteristics of the study population-Dutch girls aged 12 to 25 years who experienced at least once sexual intercourse*

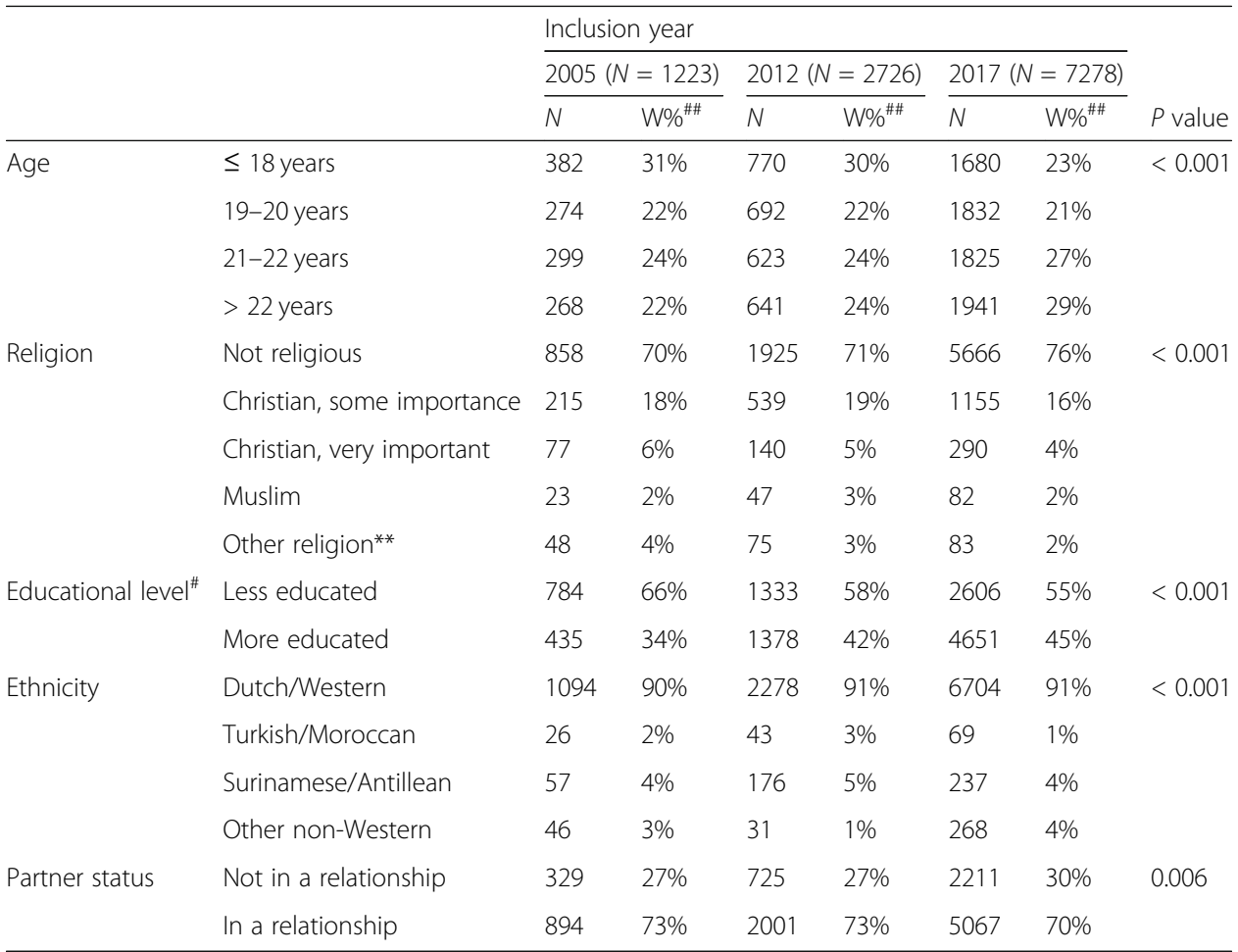

*Girls who indicated they did not use contraceptives because they currently do not have sexual contact are excluded from analyses

**Including the following: Hiduism, Judaism, Buddhism, Sikhism, Ásatrú, Mandaeism, Paganism, apostolic society, Bahá'í, ietsism/somethingism, native Indian religion, nature religions, Wicca, Yezidi, and Winti

\#Educational level was dichotomized. Higher general secondary education, pre-university education, higher vocational education, and university were classified as more educated, and all other categories as less educated \#\#Weighted percentage

increasing age of first sexual intercourse (and hence sexually experienced individuals) in the Netherlands (De Graaf, de Ter Schure, \& de Van Liere, 2020). There is a small shift towards a higher educational level (from 34 to $45 \%$ more educated young women), which resembles changes in the general population (Dutch Bureau of Statistics). Significant differences over the years were found in all demographic characteristics; however, this was often caused by the large sample size resulting in significant but small absolute differences, except for educational level.

\section{Trends in types of contraceptive used over time}

Contraception use was high among participants. In total, the most frequently used contraceptive method was oral contraceptives. We assessed trends over time for contraceptive methods used by more than $5 \%$ of young women in at least one inclusion year. The overall proportion of young women using oral contraceptive decreased significantly $(P<0.001)$, with a specific decrease between 2012 and 2017 from 64 to $53 \%$, respectively. Another significant trend over time was seen for intrauterine device (IUD) use, which increased between 2005 and 2017 from 3 to 13\%, respectively $(P<0.001)$. There was a slight increase in condom use over time, from 6 to $8 \%(P=0.009)$. No 
trends were seen for the combined use of condoms and oral contraceptives and for no contraceptive use (Table 2).

Overall, no contraceptive use is stable over time $(P=0.4)$, while SARC use decreases significantly $(P<0.001)$ and LARC use increases significantly $(P<0.001)$ (Fig. 1$)$. These trends were also found when controlling for demographic factors (age, religion, educational level, ethnicity, and partner status) (Supplementary Table 1).

Stratified by age, only among $\leq 18$ years old young women, a significantly decreasing trend in no contraceptive use was seen $(P<0.01)$. SARC use significantly decreased over time for all age groups, except for the youngest age group (all $P<0.001$ ). On the other hand, LARC use significantly increased over time for all age groups (all $P<$ $0.001)$ (Fig. 2). Trends did not differ significantly by age group $(P=0.17)$.

By religion, neither decreasing nor increasing trends were seen in no contraceptive use. For SARC use, significantly decreasing trends were seen among non-religious young women $(P<0.001)$, and young Christian women who indicate their religion is of some importance to them $(P<0.001)$. LARC use showed significantly increasing trends over time among for the same subgroups (both $P<0.001$ ). For all other religions, young Christian women to whom religion is very important, young Muslim women, and young women of other religions-no significant trends were seen in SARC and LARC use (Fig. 3). Trends differed significantly by religion $(P=0.02)$.

No significant changes in no contraceptive use were seen over the years for both educational level groups, while SARC use significantly decreased over the years among both less and more educated young women (both $P<0.001$ ). LARC use is significantly increasing among both groups (both $P<0.001$ ), but seems to be increasing more among more educated young women, since trends significantly differed by educational level $(P=0.01)$ (Fig. 4).

Stratifying by ethnicity, no contraceptive use remained stable for all groups (Dutch/ Western, Turkish/Moroccan, Surinamese/Antillean, other non-Western). SARC use significantly decreased among Dutch/Western $(P<0.001)$, Turkish/Moroccan $(P<$ $0.01)$ and Surinamese/Antillean young women $(\mathrm{P}<0.01)$, but no significant change over time was seen among other non-Western young women. LARC use significantly

Table 2 Contraception used by Dutch girls aged 12 to 25 years who experienced at least once sexual intercourse* by year of inclusion

\begin{tabular}{|c|c|c|c|c|c|c|c|}
\hline \multirow[b]{3}{*}{ No contraceptive* } & \multicolumn{6}{|c|}{ Inclusion year } & \multirow{3}{*}{$\frac{P \text { value }}{<0.001}$} \\
\hline & \multicolumn{2}{|c|}{$2005(N=1223)$} & \multicolumn{2}{|c|}{$2012(N=2726)$} & \multicolumn{2}{|c|}{$2017(N=7278)$} & \\
\hline & 109 & $9 \%$ & 129 & $6 \%$ & 415 & $8 \%$ & \\
\hline Oral contraceptive & 745 & $61 \%$ & 1778 & $64 \%$ & 3925 & $53 \%$ & \\
\hline Condoms & 78 & $6 \%$ & 194 & $8 \%$ & 604 & $8 \%$ & \\
\hline Oral contraceptive and condoms & 231 & $19 \%$ & 383 & $14 \%$ & 1100 & $14 \%$ & \\
\hline Injectable contraceptive & 8 & $1 \%$ & 25 & $1 \%$ & 85 & $2 \%$ & \\
\hline Contraceptive patch & 1 & $0 \%$ & 5 & $0 \%$ & 5 & $0 \%$ & \\
\hline Vaginal ring contraceptive & 9 & $1 \%$ & 40 & $1 \%$ & 70 & $1 \%$ & \\
\hline Contraceptive implant & 6 & $0 \%$ & 14 & $1 \%$ & 103 & $2 \%$ & \\
\hline Intrauterine device & 32 & $3 \%$ & 154 & $6 \%$ & 960 & $13 \%$ & \\
\hline Other & 4 & $0 \%$ & 4 & $0 \%$ & 11 & $0 \%$ & \\
\hline
\end{tabular}

*Girls who indicated they did not use contraceptives because they currently do not have sexual contact are excluded from analyses 


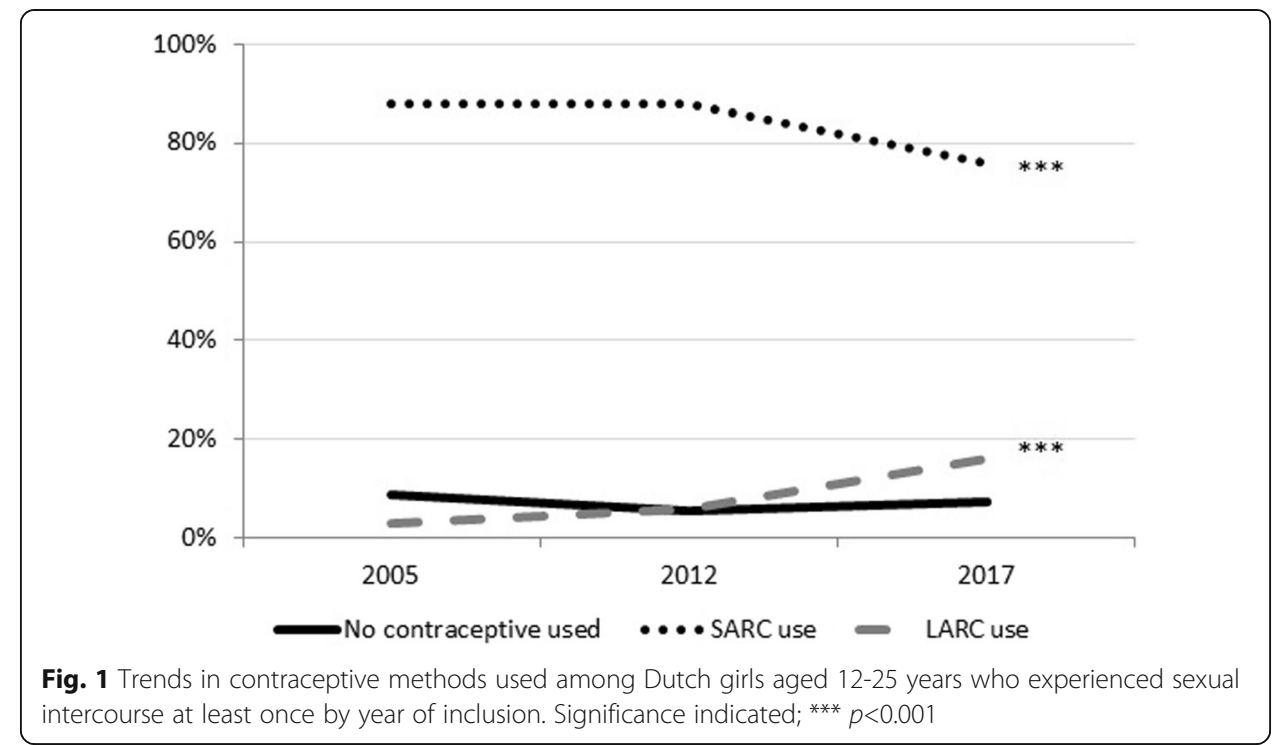

increased only among Dutch/Western young women $(P<0.001)$. Possibly partly due to the small cell counts, increases in LARC use among Turkish/Moroccan, Surinamese/ Antillean, and other non-Western young women were non-significant. Overall trends neither differed significantly by ethnic group $(P=0.06)$ (Fig. 5).

SARC and LARC use did not seem to differ between single young women and women in a relationship. In both groups, SARC use significantly decreased, while LARC use significantly increased. There was no significant interaction between relationship status and year of inclusion, so these trends were the same for young women in and outside a relationship $(P=.152)$ (Fig. 6).

\section{Discussion}

We assessed trends in types of contraceptives used, in long-acting reversible contraceptive (LARC) use and in short-acting reversible contraceptive (SARC) use over a period of 12 years by demographic factors among young women aged 12 to 25 years, with experience of sexual intercourse in the Netherlands. Overall, SARC use was decreasing while LARC use was increasing. The decrease in SARC use could be mainly attributed to a decrease in oral contraceptive use, while a significant increase in the use of intrauterine devices could account for the rise in LARC use. This increase in LARC use confirms what was found in several earlier (mainly USA, but also French, UK, and subSaharan African) studies (Adedini et al., 2019; Connolly et al., 2014; Eisenberg, Allsworth, Zhao, \& Peipert, 2012; Kavanaugh \& Jerman, 2018; Law et al., 2016; Moreau et al., 2013; Pazol et al., 2016; Walsh-Buhi \& Helmy, 2018; Whitaker, Sisco, Tomlinson, Dude, \& Martins, 2013). However, the specific type of LARC that is increasingly used varies per study. The National Survey of Family Growth for example, found that the increase in LARC use was driven by an increase in IUD, whereas in a study among US college students, this trend was driven by implant use. Irrespective of the specific method that drives the trend, LARC use can be considered beneficial for women. LARC is, once inserted, independent of user compliance and found to be very effective for pregnancy prevention (Polis et al., 2016; Shoupe, 2016; Stoddard et al., 2011). An increase in its use might therefore eventually lead to a decrease in unwanted pregnancies 


\section{$\underline{\text { No contraceptive use }}$}

20

10
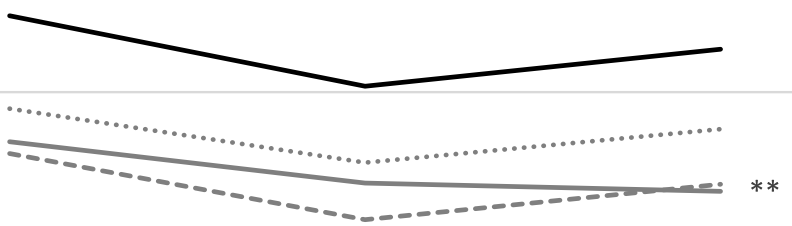

0

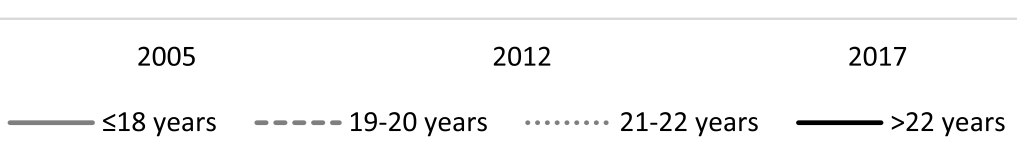

\section{Short-acting reversible contraception use}

100

80

60

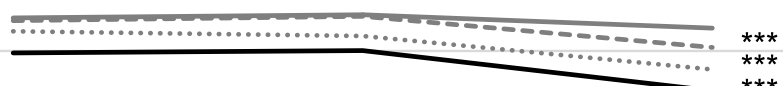

40

40

20

0

2005

2012

2017

$\leq 18$ years $-\cdots---19-20$ years

21-22 years

$>22$ years

\section{Long-acting reversible contraception use}

30

20

10

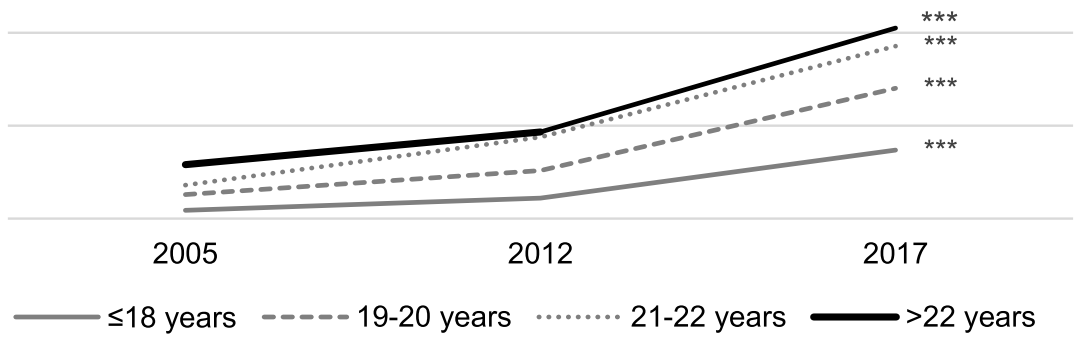

Fig. 2 Trends over time in contraceptive use by age. Trends did not differ significantly by age group $(p=.169)$. Significance indicated; ${ }^{* *} p<0.01,{ }^{* * *} p<0.001$

and abortions (Biggs, Rocca, Brindis, Hirsch, \& Grossman, 2015; Hubacher, Spector, Monteith, Chen, \& Hart, 2017).

Compared to the increase in LARC use, the decrease in SARC was less often confirmed in the literature. Among young women aged 12 to 16 years in the Netherlands, oral contraceptive use seems to be rather stable between 2001 and 2017 (Stevens et al., 2018). This trend is also stable among women aged 16-44 in Ireland between 2008 and 2013 (O’Mahony, Liddy, Barry, \& Bennett, 2015), as well as among women aged 15-44 years in the USA between 2008 and 2014 (Kavanaugh \& Jerman, 2018). The use of 


\section{No contraceptive use}

40

30

20

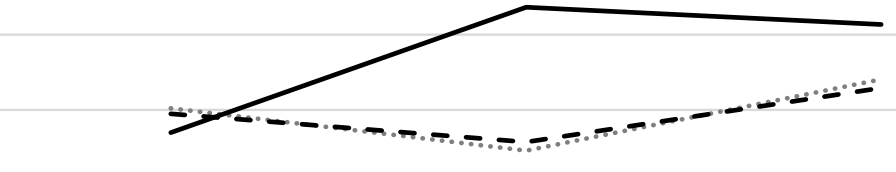

10

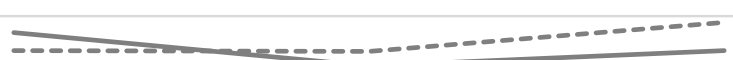

0

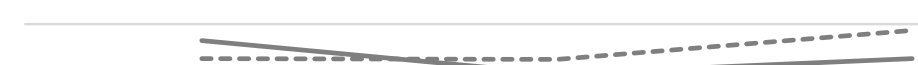

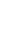

2005

2012

2017

No religion

- - - - Christian, some importance

Christian, very important

Muslim

- - - Other religion

\section{Short-acting reversible contraception use}

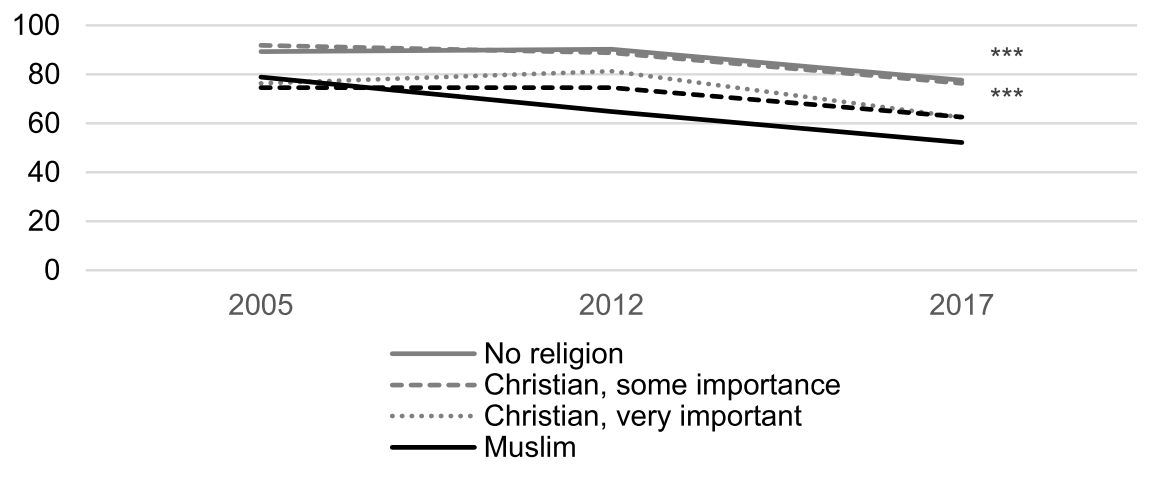

\section{Long-acting reversible contraception use}

30

20

10

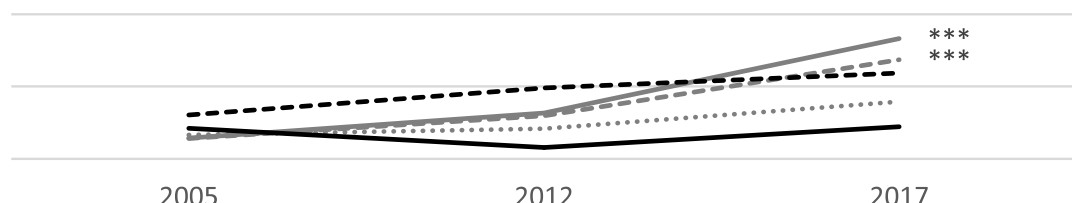

2005

2012

2017

No religion

----- Christian, some importance

Christian, very important

Muslim

- - - Other religion

Fig. 3 trends over time in contraceptive use by religion. Trends differed significantly by religion group $(p=.024)$. \# Numbers in some groups are small, explaining the large proportional differences tha show no statistically significant trend. Significance indicated; ** $p<0.01,{ }^{* * *} p<0.001$

other types of SARC (patch, vaginal ring, and injectable contraceptives) slightly declined in the USA from 8 to 7\% between 2011 and 2014 (Walsh-Buhi \& Helmy, 2018). These results suggest that in some other countries, the increase in LARC use results in 


\section{No contraceptive use}

20

10

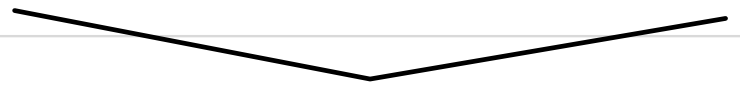

0

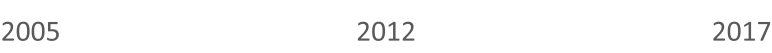

Less educated ----- More educated

\section{Short-acting reversible contraception use}

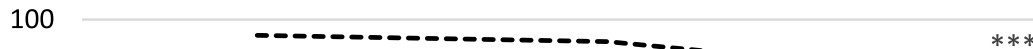

80

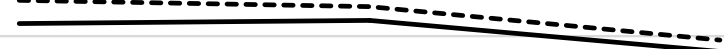

$* * *$

60

40

20

0

2005

2012

2017

Less educated

More educated

\section{Long-acting reversible contraception use}

30

20

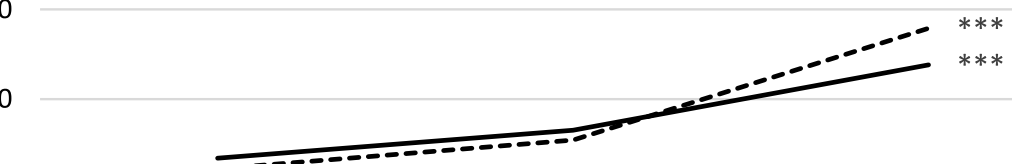

10

0

Less educated

-.-.-More educated

Fig. 4 Trends over time in contraceptive use by educational level. Trends differed significantly by education group ( $p=.010)$. Significance indicated; ** $p<0.01,{ }^{* * *} p<0.001$

an increase in the use of modern contraceptives in general, whereas in the Netherlands, the increase in LARC use almost equals the decrease in SARC use.

The increasing trend in LARC use combined with the decreasing trend in SARC use and stable trends in no contraceptive use suggests that at least part of the young women in the Netherlands with experience of contraceptive use switch contraceptive method. Switching from SARC to LARC has been shown in the National Survey of Family Growth in which women aged 15-44 years who were not satisfied with their hormonal SARC were twice as likely to currently use LARC (Kavanaugh, Jerman, \& 


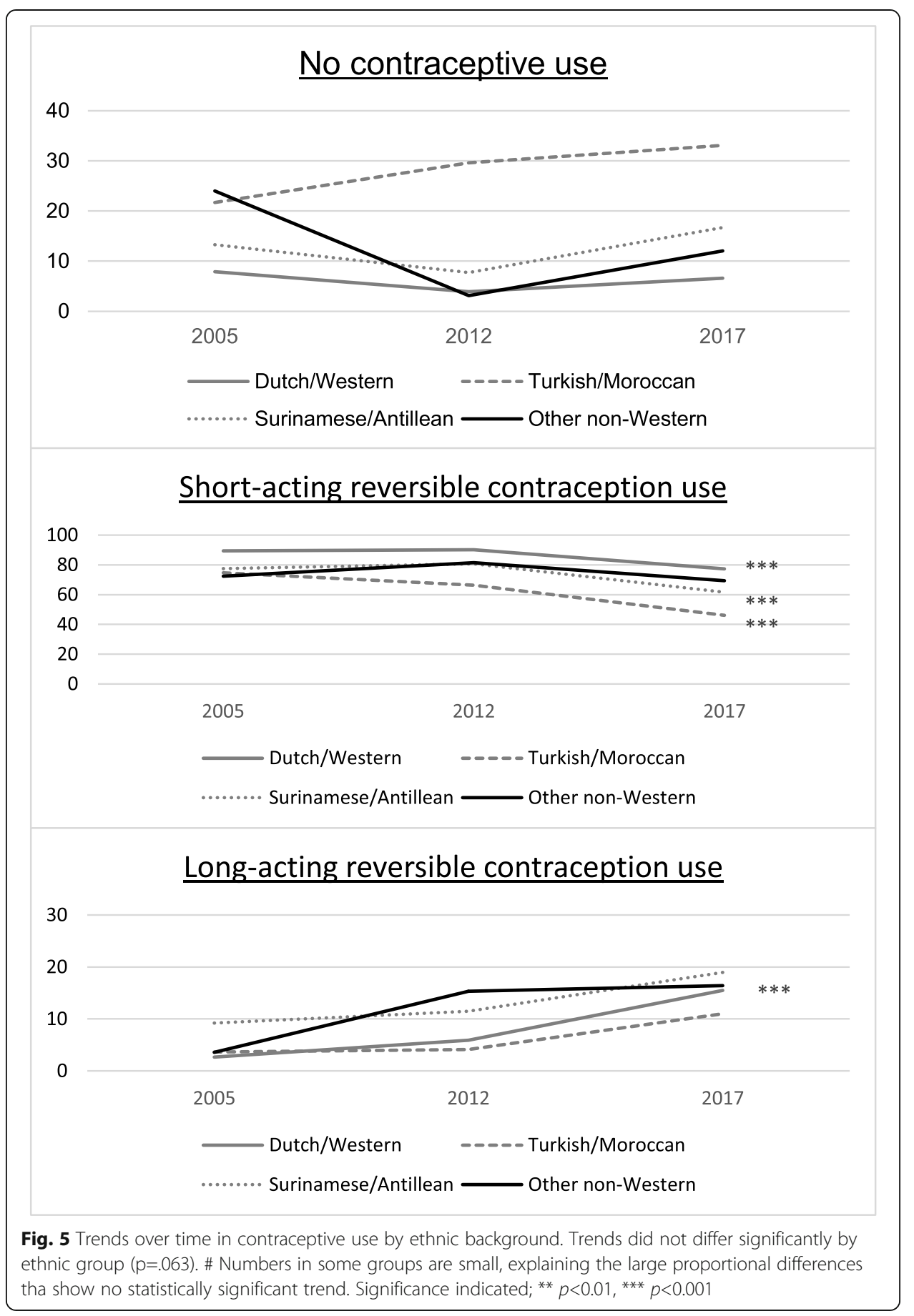

Finer, 2015). Also, Law et al. (2016) found women aged 15-44 years switching towards LARC methods between 1999 and 2014. Additionally, more younger women, thus new users, started using LARC. This might be caused by availability of more diverse and newer LARC methods. Accessibility to LARC methods, either through online information or personal information by physicians, might also influence the increase in LARC uptake. Hubacher and colleagues (2017) studied LARC acceptance among young women aged 18-29 years who visited health centers with a request for oral or injectable 


\section{$\underline{\text { No contraceptive use }}$}

20

10

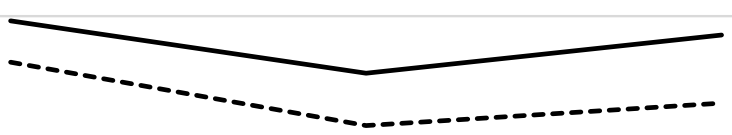

0

2005

2012

2017

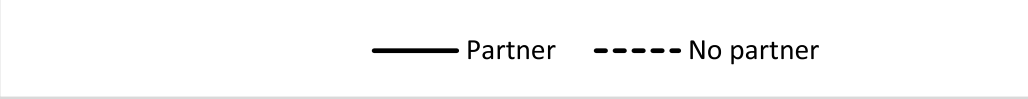

\section{Short-acting reversible contraception use}

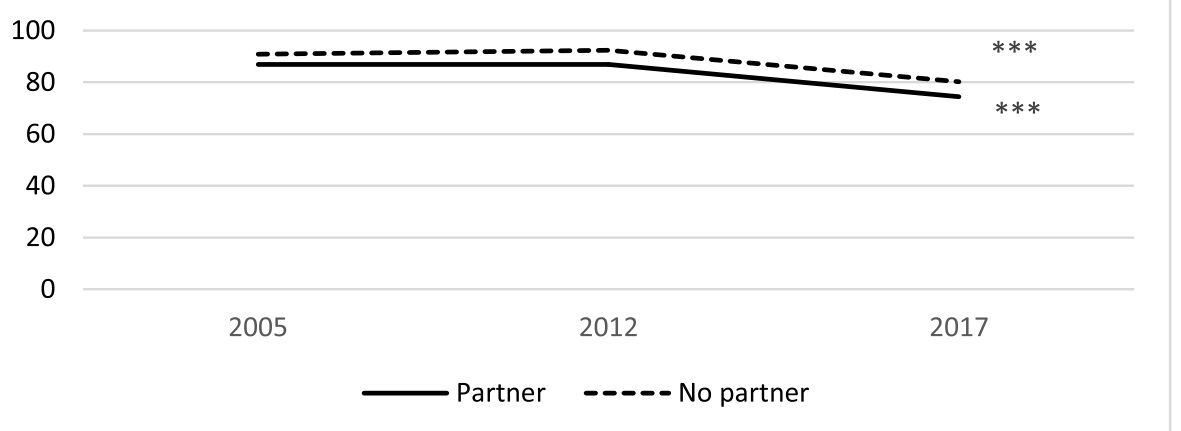

\section{Long-acting reversible contraception use}

30

20

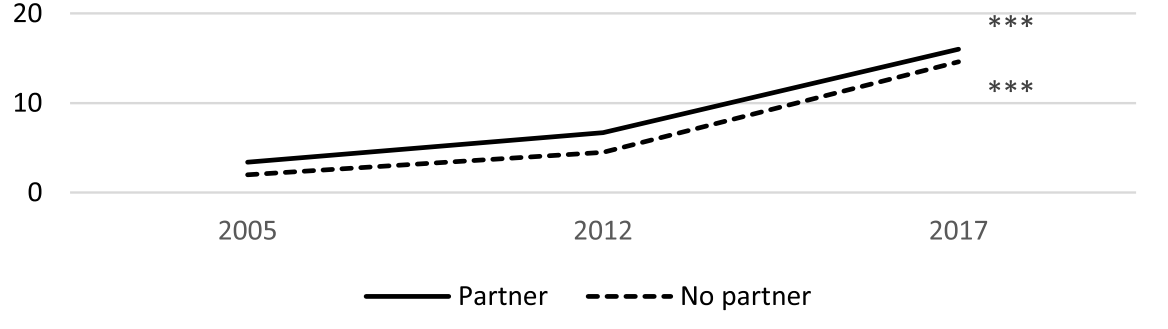

Fig. 6 Trends over time in contraceptive use by partner status. Trends differed significantly by education group ( $p=.152$ ). Significance indicated; ${ }^{* *} p<0.01,{ }^{* * *} p<0.001$

contraceptives. Participants were randomized to get either SARC or LARC. Among these initially SARC-preferring participants, LARC use was found to be highly acceptable, with a probability of method continuation of $78 \%$ vs. $53 \%$ in the randomized SARC group. The Dutch College of General Practitioners accepted a new standard for contraception in 2011. One of the core guidelines in this standard is to give information about a broad array of contraceptive methods, to enable people to make wellinformed personal choices. This might partly explain the gradual diversification in contraceptive choices of young women in the Netherlands. 
Not all demographic groups shift towards LARC use equally. A closer look at various demographic groups revealed interesting differences in these trends. For young women $\leq 18$ years, the increase in LARC use coincided with a decrease in no contraceptive use, which is a positive finding in terms of pregnancy prevention. For Turkish/Moroccan and Surinamese/Antillean young women, there was a significant decrease in SARC use, but there were no significant trends for either no contraceptive use or LARC use. It seems that part of these young women shifted to no contraceptive use and part to LARC use, which suggests an increase in risk for some of the young women with these immigrant backgrounds. Trends significantly differed by religion and educational level. SARC use decreased and LARC use increased only among young non-religious women and young Christian women for whom religion is of some importance, not among other religious subgroups. LARC use also seemed to increase stronger among more educated young women compared to less educated young women. These findings add to the literature, since these trends are rarely studied and if studied, trends were similar in all age, ethnic, and education groups (Adedini et al., 2019; Kavanaugh \& Jerman, 2018). This study was also the first to differentiate trends in contraceptive use by the importance of religion among Christian young women.

This study has several limitations. First, we were unable to assess some demographic factors for which trends might differ (e.g., income ${ }^{20,27}$, geographical residence ${ }^{22,47}$, or maternal educational level ${ }^{49}$ ) because of the broad focus of the sex under the age of 25 studies. However, based on current literature, we were able to assess the most commonly found demographic factors influencing contraception use or choice. Second, we were unable to extensively assess motives and attitudes regarding contraceptive choices. From our perspective, it is important that women are able to choose the contraceptive method that fits their needs and expectations. Insight into motives and attitudes towards SARC and LARC as contraceptive methods enables more tailored advice on contraceptive methods. Our data also does not give insight in possible hormonal motives for the decrease in oral contraceptives, since in 2017 no distinction was made between hormonal and copper IDU and we did not assess other non-hormonal methods like periodic abstinence and withdrawal methods. Last, this study is not a longitudinal study, preventing insight into what proportion of increase in LARC is caused by a switch from SARC to LARC.

In conclusion, SARC use has decreased and LARC use has increased between 2005 and 2017 in the Netherland among young women aged 12-25 years who experienced sexual intercourse at least once. Since the vast majority of Dutch young women used oral contraceptives for the past decades, these trends might eventually lead to a further decrease in unwanted pregnancies and abortions. These trends in SARC use and LARC use were absent or less steep among young Christian women for whom religion is very important, young Muslim women, young women with other religions, and less educated young women.

To avoid unplanned pregnancies, it is important that (young) women use the kind of contraceptive that fits their personal situation best. If a contraceptive method fits the needs and requirements of a woman, she is more likely to use this method more consistently and correctly. This results in better protection against unplanned and potentially unwanted pregnancy and less abortion (Sridhar, Rodriguez, Roque, \& Abutouk, 2016). It is therefore important that healthcare professionals, sexuality education, as 
well as online platforms inform about a broad range of contraceptive methods. Furthermore, preventive efforts should focus especially on those groups that lag behind in the shift towards LARC, i.e., religious and lower educated young women.

\section{Supplementary information}

Supplementary information accompanies this paper at https://doi.org/10.1186/s41118-020-00078-3.

Additional file 1: Table S1. Multivariable multinomial logistic regression of the association between year of inclusion and contraceptive use corrected for demographic factors*.

Abbreviations

SARC: Short-acting reversible contraception; LARC: Long-acting reversible contraception

\section{Acknowledgements}

Fifteen Municipal Health Services (GGDs) made a major contribution to the recruitment of a large database containing national as well as regional data.

\section{Authors' contributions}

The design of this study was made by HdG and EM. Data analysis and preparation of the manuscript were done by EM. Design of the sex under the age of 25 studies was done by a collaboration between HdG, SM, and CW. All coauthors contributed to feedback and improving the manuscript taking into account their expertise. All authors read and approved the final manuscript.

\section{Funding}

This research was supported by a grant from the Dutch National Institute for Public Health and the Environment (RIVM), The Netherlands.

\section{Availability of data and materials}

The datasets used and/or analyzed during the current study are available from the corresponding author on reasonable request.

\section{Competing interests}

The authors have no competing interests.

\section{Author details}

${ }_{1}^{1}$ Rutgers, Programme Knowledge Development, Utrecht, The Netherlands. ${ }^{2}$ STI AIDS Netherlands, Youth Programme, Amsterdam, The Netherlands.

Received: 1 November 2019 Accepted: 7 May 2020

Published online: 24 May 2020

\section{References}

Adedini, S. A., Omisakin, O. A., \& Somefun, O. D. (2019). Trends, patterns and determinants of long-acting reversible methods of contraception among women in sub-Saharan Africa. PLOS One, 14, 1-16. https://doi.org/10.1371/journal.pone.0217574.

Biggs, M. A., Rocca, C. H., Brindis, C. D., Hirsch, H., \& Grossman, D. (2015). Did increasing use of highly effective contraception contribute to declining abortions in lowa? Contraception, 91, 167-173. https://doi.org/10.1016/j.contraception.2014.10.009.

Cahill, N., Sonneveldt, E., Stover, J., Weinberger, M., Williamson, J., Wei, C., et al. (2018). Modern contraceptive use, unmet need, and demand satisfied among women of reproductive age who are married or in a union in the focus countries of the Family Planning 2020 initiative: a systematic analysis using the Family Planning Estimation Tool. The Lancet, 391, 870882. https://doi.org/10.1016/S0140-6736(17)33104-5.

Carrasco-Garrido, P., López De Andrés, A., Hernández-Barrera, V., Jiménez-Trujillo, I., Esteban-Peña, M., Pérez-Farinós, N., \& Jiménez-García, R. (2016). Trends in the use of oral contraceptives among adolescents and young women in Spain. Reproductive Health, 13, 1-9. https://doi.org/10.1186/s12978-016-0239-4.

Connolly, A., Pietri, G., Yu, J., \& Humphreys, S. (2014). Association between long-acting reversible contraceptive use, teenage pregnancy, and abortion rates in England. International Journal of Women's Health, 6, 961-974. https://doi.org/10.2147/ IJWH.S64431.

Cuzick, J. A. (1985). Wilcoxon-type test for trend. Statistics in Medicine, 4, 87-90.

Daniels, K., Daugherty, J., Jones, J., \& Mosher, W. (2015). Current contraceptive use and variation by selected characteristics among women Aged 15-44: United States, 2011-2013. National Health Statistics Reports, 86, 1-14. http://www.ncbi.nlm. nih.gov/pubmed/26556545.

Darroch, J. E., \& Singh, S. (2013). Trends in contraceptive need and use in developing countries in 2003, 2008, and 2012: an analysis of national surveys. The Lancet, 381, 1756-1762. https://doi.org/10.1016/50140-6736(13)60597-8.

Davtyan, C. (2000). Evidence-based case review: contraception for adolescents. Western Journal of Medicine, 172, 166-171. https://doi.org/10.1136/ewjm.172.3.166.

De Graaf, H., de Ter Schure, J., \& de Van Liere, G. A. F. S. (2020). How old are young people when they start having sex? Methodological challenges in answering this question. Manuscript submitted for publication.

De Graaf, H., Vanwesenbeeck, I., \& Meijer, S. (2014). Educational differences in adolescents' sexual health: a pervasive phenomenon in a national Dutch sample. Jounal of Sex Research, 52, 747-757. 
De Graaf, H., Vanwesenbeeck, I., Meijer, S., Woertman, L., \& Meeus, W. (2009). Sexual trajectories during adolescence: relation to demographic characteristics and sexual risk. Archives of Sexual Behavior, 38, 276-282.

De Graaf, H., Verbeek, M., Van den Borne, M., \& Meijer, S. (2018). Offline and online sexual risk behavior among youth in the Netherlands: findings from "Sex under the Age of 25". Frontiers in Public Health, 6, 72. https://doi.org/10.3389/fpubh.2018. 00072 .

Deitch, J. \& Stark, L. (2019). Adolescent demand for contraception and family planning services in low- and middle-income countries: a systematic review. Global Public Health, 0, 1-19. doi:https://doi.org/10.1080/17441692.2019.1583264.

Eisenberg, D. L., Allsworth, J. E., Zhao, Q., \& Peipert, J. F. (2012). Correlates of dual-method contraceptive use: an analysis of the national survey of family growth (2006-2008). Infectious Diseases in Obstetrics and Gynecology, 2012. https://doi.org/10. 1155/2012/717163.

Hopkins, K., Hubert, C., Coleman-Minahan, K., Stevenson, A. J., White, K., Grossman, D., \& Potter, J. E. (2018). Unmet demand for short-acting hormonal and long-acting reversible contraception among community college students in Texas. Journal of American College Health, 66, 360-368. https://doi.org/10.1080/07448481.2018.1431901.

Hubacher, D., Spector, H., Monteith, C., Chen, P. L., \& Hart, C. (2017). Long-acting reversible contraceptive acceptability and unintended pregnancy among women presenting for short-acting methods: a randomized patient preference trial. American Journal of Obstetrics and Gynecology, 216, 101-109. https://doi.org/10.1016/j.ajog.2016.08.033.

Ihongbe, T. O., \& Masho, S. W. (2017). Changes in the use of long-acting reversible contraceptive methods among U.S. nulliparous women: results from the 2006-2010, 2011-2013, and 2013-2015 National Survey of Family Growth. Journal of Women's Health, 27, 245-252. https://doi.org/10.1089/jwh.2017.6609.

Inchley, J., Currie, D., Young, T., Samdal, O., Torsheim, T., Augustson, L., ... Barnekow, V. (2016). Growing up unequal: gender and socioeconomic differences in young people's health and well-being. Copenhagen, Denmark: WHO. http://www.euro. who.int/_data/assets/pdf_file/0003/303438/HSBC-No.7-Growing-up-unequal-Full-Report.pdf?ua=1.

Karaçam, Z., \& Ançel, G. (2009). Depression, anxiety and influencing factors in pregnancy: a study in a Turkish population. Midwifery, 25, 344-356. https://doi.org/10.1016/j.midw.2007.03.006.

Kavanaugh, M. L., \& Jerman, J. (2018). Contraceptive method use in the United States: trends and characteristics between 2008, 2012 and 2014. Contraception, 97, 14-21.

Kavanaugh, M. L., Jerman, J., \& Finer, L. B. (2015). Changes in use of long-acting reversible contraceptive methods among U.S. women, 2009-2012. Obstetrics and Gynecology, 126, 917-927. https://doi.org/10.1097/AOG.0000000000001094.

Kinoshita, T., Tanaka, S., Inagaki, M., Takeuchi, M., \& Kawakami, K. (2018). Prescription pattern and trend of oral contraceptives in Japan: a descriptive study based on pharmacy claims data (2006-2014). Sexual \& Reproductive Healthcare, 17, 50-55.

Kramer, R. D., Higgins, J. A., Godecker, A. L., \& Ehrenthal, D. B. (2018). Racial and ethnic differences in patterns of long-acting reversible contraceptive use in the United States, 2011-2015 Contraception, 97, 399-404. doi:https://doi.org/10.1016/j. contraception.2018.01.006

Law, A., Pilon, D., Lynen R, Laliberté, F., Gozalo, L., Lefebvre, P. \& Sheng Duh, M. (2016). Retrospective analysis of the impact of increasing access to long acting reversible contraceptives in a commercially insured population. Reproductive Health, 13. doi:https://doi.org/10.1186/s12978-016-0211-3.

Lindberg, L. D., Santelli, J. S., \& Desai, S. (2018). Changing patterns of contraceptive use and the decline in rates of pregnancy and birth among U.S. adolescents, 2007-2014. Journal of Adolescent Health, 63, 253-256. https://doi.org/10.1016/j. jadohealth.2018.05.017.

Moreau, C., Bohet, A., Hassoun, D., Teboul, M., \& Bajos, N. (2013). Trends and determinants of use of long-acting reversible contraception use among young women in France: results from three national surveys conducted between 2000 and 2010. Fertility and Sterility, 100, 451-458. https://doi.org/10.1016/j.fertnstert.2013.04.002.

Ngui, E. M., Greer, D. M., Bridgewater, F. D., Salm Ward, T. C., \& Cisler, R. A. (2017). Trends and progress in reducing teen birth rates and the persisting challenge of eliminating racial/ethnic disparities. Journal of Racial and Ethnic Health Disparities, 4 , 615-622.

O'Mahony, L., Liddy, A. M., Barry, M., \& Bennett, K. (2015). Hormonal contraceptive use in Ireland: trends and co-prescribing practices. British Journal of Clinical Pharmacology, 80, 1315-1323. https://doi.org/10.1111/bcp.12755.

Pazol, K., Daniels, K., Romero, L., Warner, L., \& Barfield, W. (2016). Trends in long-acting reversible contraception use in adolescents and young adults: new estimates accounting for sexual experience. Journal of Adolescent Health, 59, 438-442. https://doi.org/10.1016/j.jadohealth.2016.05.018.

Picavet, C., Goenee, M., \& Wijsen, C. (2013). Characteristics of women who have repeat abortions in the Netherlands. The European journal of Contraception \& Reproductive Health Care, 18, 327-334. https://doi.org/10.3109/13625187.2013.820824.

Polis, C. B., Bradley, S. E. K., Bankole, A., Onda, T., Croft, T., \& Singh, S. (2016). Typical-use contraceptive failure rates in 43 countries with Demographic and Health Survey data: summary of a detailed report. Contraception, 94, 11-17. https://doi. org/10.1016/j.contraception.2016.03.011.

Ponce de Leon, R. G., Ewerling, F., Serruya, S., Silveira, M. F., Sanhueza, A., Moazzam, A., et al. (2019). Contraceptive use in Latin America and the Caribbean with a focus on long-acting reversible contraceptives: prevalence and inequalities in 23 countries. The Lancet Global Health, 7, e227-e235. https://doi.org/10.1016/S2214-109X(18)30481-9.

Rodriguez, J., Abutouk, M., Roque, K., \& Sridhar, A. (2015). Trends and patterns of hormonal contraceptive prescribing for adolescents in primary care in the UK. BMJ Sexual \& Reproductive Health, 41, 216-222. https://doi.org/10.1136/jfprhc-2013100724.

Sedgh, G., Finer, L. B., Bankole, A., Eilers, M. A., \& Singh, S. (2015). Adolescent pregnancy, birth, and abortion rates across countries: levels and recent trends. Journal of Adolescent Health, 56, 223-230. https://doi.org/10.1016/j.jadohealth.2014.09.007.

Shoupe, D. (2016). LARC methods: entering a new age of contraception and reproductive health. Contraception and Reproductive Medicine, 1, 1-9. https://doi.org/10.1186/s40834-016-0011-8.

Sridhar, A., Rodriguez, J., Roque, K., \& Abutouk, M. (2016). Personalized contraceptive counseling: helping women make the right choice. Open Access Journal of Contraception, 89. doi:https://doi.org/10.2147/oajc.s81546.

Stevens, G., van Dorsselaer, S., Boer, M., de Roos, S., Duinhof, E., ter Bogt, T.,..., van den Eijnden, R., Kuyper, L., Visser, D. Vollebergh, W., \& de Looze, M. (2018). HBSC 2017. Gezondheid en welzijn van jongeren in Nederland. [HBSC 2017. Health and well-being of adolescents in the Netherlands]. Utrecht: Utrecht University. 
Stoddard, A., McNicholas, C., \& Peipert, J. F. (2011). Efficacy and safety of long-acting reversible contraception. Drugs, 71, 969980. https://doi.org/10.2165/11591290-000000000-00000.

Ugaz, J. I., Chatterji, M., Gribble, J. N., \& Mitchell, S. (2015). Regional trends in the use of short-acting and long-acting contraception accessed through the private and public sectors. International Journal of Gynecology \& Obstetrics, 130, e3e7. https://doi.org/10.1016/j.jigo.2015.03.021.

United Nations, Department of Economic and Social Affairs, Population Division (2019). Contraceptive Use by Method 2019: Data Booklet.

Walsh, T. L., Frezieres, R. G., Peacock, K., Nelson, A. L., Clark, V. A., Bernstein, L., \& Wraxalle, B. G. D. (2004). Effectiveness of the male latex condom: combined results for three popular condom brands used as controls in randomized clinical trials. Contraception, 70, 407-413.

Walsh-Buhi, E. R., \& Helmy, H. L. (2018). Trends in long-acting reversible contraceptive (LARC) use, LARC use predictors, and dual-method use among a national sample of college women. Journal of American College Health, 66, 225-236.

Whitaker, A. K., Sisco, K. M., Tomlinson, A. N., Dude, A. M., \& Martins, S. L. (2013). Use of the intrauterine device among adolescent and young adult women in the United States from 2002 to 2010. Journal of Adolescent Health, 53, 401-406. https://doi.org/10.1016/j.jadohealth.2013.04.011.

Yanikkerem, E., Ay, S., \& Piro, N. (2013). Planned and unplanned pregnancy: effects on health practice and depression during pregnancy. Journal of Obstetrics and Gynaecology Research, 39, 180-187. https://doi.org/10.1111/j.1447-0756.2012.01958.x.

\section{Publisher's Note}

Springer Nature remains neutral with regard to jurisdictional claims in published maps and institutional affiliations.

Submit your manuscript to a SpringerOpen ${ }^{\odot}$ journal and benefit from:

- Convenient online submission

- Rigorous peer review

- Open access: articles freely available online

High visibility within the field

- Retaining the copyright to your article

Submit your next manuscript at $\boldsymbol{\nabla}$ springeropen.com 